\title{
Страсти вокруг котельной
}

В теплоэнергетике в концентрированном виде сосредоточены очень многие проблемы, с которыми сталкиваются и экономика, и социальная система России на протяжении последних более чем тридцати лет. Важнейшие среди них: социальная роль и значимость обеспечения значительной части населения страны теплом из «внешних источников» (увы, многие наши граждане все еще отапливают жилье дровами и имеют «удобства» на улице); особенность материально-технологических активов, созданных в рамках системы централизованного планирования и управления и ускоренной индустриализации и урбанизации; «хронический диагноз» ведомственности и клановых и корпоративных интересов; неизменная склонность к мнимой простоте и администрируемости при формировании системы управления и регулирования сложнейших экономических процессов.

Важно то, что реформирование и преображение системы теплоснабжения урбанизированных поселений нашей необъятной Родины происходят тогда, когда в мире все меняется под влиянием современного этапа научно-технического развития (включая «бум» новых информационных технологий и, в целом, формирование новой модели взаимодействия человека и внешней среды). Безусловно, эти процессы идут везде с разной скоростью: на смену углю в качестве источника тепло- и электроэнергии, по мере перехода экономики той или иной страны на новый уровень развития приходят альтернативные источники энергии. Системы производства тепловой энергии на основе крупных объектов (станций) испытывают все большее давление со стороны распределенных источников генерации (эффекты масштаба и когенерации уже не являются универсальными и не могут служить единственной основой для выработки и принятия решений).

Переход к новой электро- и теплоэнергетике немыслим вне учета названных особенностей: с одной стороны, исторической и «естественной» специфики России (страны регионов), a с другой - процесса быстро идущих изменений в технике и технологиях. Целью реформ, которые с разной степенью успешности проводятся в экономике нашей страны и в ее значимой составляющей - энергетике, является стремление повысить 
эффективность использования и потребления ресурсов (в данном случае - электроэнергии и тепла), а также открыть дорогу прогрессивным процессам в изменении технологического уровня и все возрастающего значения социальной и экологической составляющих.

При удачном соединении страновых условий и особенностей с возможностями, предоставляемыми современными технологиями, а также при условии создания и применения действенных процедур регулирования, результаты и сроки достижения приемлемого уровня социальной, экологической, экономической эффективности не заставят себя долго ждать.

К сожалению, в случае рассогласования отмеченных составляющих говорить об эффективности не приходится. Растут издержки и тарифы, население все больше увязает в долгах за жилищно-коммунальные услуги, промышленные потребители все чаще «голосуют рублем», переходя на собственные источники генерации, финансовые возможности генерирующих компаний уменьшаются, а с ними увеличивается и доля физически изношенного оборудования. В этой ситуации все чаще приходится заниматься «пожаротушением»- например, срочно расширять сферу применения государственно-частного партнерства не для решения проблем развития, а для «латания дыр». Приведенный на страницах настоящей тематической подборки анализ реализации проектов ГЧП в энергетическом секторе РФ показал, что «большинство из них имеют мелкий масштаб и относятся к муниципальному уровню. В основном это проекты, направленные на поддержание теплосетей и объектов энергоснабжения в рабочем состоянии. Они не способны привести к значительным изменениям в отрасли и не способствуют созданию новых и модернизации действующих объектов энергоснабжения» (статья Л.А. Толстолесовой, М.С. Воробьевой, Н. Н. Юмановой).

И энергетика в целом, и тем более, производство тепла и его поставка потребителям, сформированные в рамках тех подходов и традиций индустриального мышления, которые превалировали в экономике централизованного планирования и управления, ожидаемо оказались в числе высокомонополизированных секторов. Особенно это касается относительно замкнутых и обособленных систем теплоснабжения. Отсюда берут начало почти 
все основные недостатки отрасли: нерациональное использование ресурсов, несоответствие цены качеству услуг, отсутствие стимулов к внедрению инноваций, нарастание экономической, экологической, общественной неэффективности.

Авторами этого номера в качестве иллюстрации того, как можно добиться серьезных успехов в деле экономии энергии и выдерживания допустимых уровней ее расходования, приведен обзор практики принятия решений в данной области Государственного комитета обороны в годы Великой Отечественной войны (статья Н.С. Симонова). Но этот пример относится к практике другой, весьма специфической экономической системы.

Выход из сложившейся в современной России ситуации, который был в конце концов найден, вполне логичен и правомерен для рыночной экономики: при отсутствии конкуренции физически доступных товаров (услуг) со стороны поставщиков сформировать им виртуальную замену. На роль подобного «фантома» в случае производства тепла была призвана так называемая «альтернативная котельная», некий виртуальный источник тепловой энергии, который мог бы обеспечить производство тепла в данной местности наилучшим образом, используя самые современные технологии. Важно, что технологические составляющие год от года должны меняться в сторону роста эффективности.

Применение в качестве индикатора издержек «альтернативной котельной» особых сомнений не вызывает - и логично, и в общем приемлемо с методической точки зрения. Самые большие сложности возникают, как это бывало не раз, при переходе от теоретически выстроенной схемы к ее практической реализации. А именно: какие технологии брать за основу, какие и где получать индикаторы, характеризующие издержки факторов производства.

Фактически тот предельно допустимый уровень издержек (тарифа на их основе), который характеризует «альтернативную котельную», является, по меткому выражению Е.А. Косоговой, «ценой ухода» потребителей к альтернативным поставщикам. Поэтому главная экономическая проблема для регуляторов и действующих игроков рынка теплоэнергии - формирование приемлемой «формулы цены входа», которая позволяла бы остаться в данном бизнесе и успешно его развивать. 
Результативное применение образа «альтернативная котельная» в значительной мере определяется принимаемой и реализуемой схемой государственного регулирования формирования рынка тепла, с одной стороны, а с другой - связью данных процессов с научно-технической политикой в стране. Несомненно, что «достижение индикативного уровня (тарифа) должно сигнализировать контрольным органам о несостоятельности компании по выполнению своих обязательств по теплоснабжению потребителей и необходимости принятия соответствующих организационных мер» (статья В. А. Стенникова и А.В. Пеньковского).

Одно из важнейших условий - учет местных особенностей и обстоятельств. Именно это, как показано на страницах настоящей подборки, является причиной успешной реализации механизма «альтернативной котельной» в г. Рубцовске Алтайского края (статья Е.А. Косоговой).

Все попытки при регулировании сложных систем пренебречь местной спецификой приводят к результатам прямо противоположным - при достижении простоты и мнимой управляемости процессом формирования рынка тепла обеспечить рост социальной и экономической результативности в долгосрочном периоде не удается. Последнее возможно только в рамках консенсусного подхода к выработке решений с учетом мнений производителей тепло- и электроэнергии, ее поставщиков и, вне сомнения, самих потребителей.

Главный редактор «ЭКО»

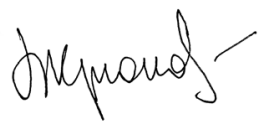

КРЮКОВ В.А. 